\title{
CARDIOGRAPHIC ASSESSMENT OF PULMONARY VASCULAR DISEASE IN VENTRICULAR SEPTAL DEFECT
}

\author{
BY \\ ARTHUR HOLLMAN, J. F. GOODWIN, AND L. BASTA* \\ From the Department of Medicine, Postgraduate Medical School of London, Hammersmith Hospital \\ Received November 16, 1961
}

The electrocardiogram in ventricular septal defect has long been recognized as affording some ndication of the size of the defect and of the hæmodynamic disturbance. In 1954, Wood, Magidson, and Wilson reported that small defects and some defects of medium size had normal cardiograms, but that in larger defects evidence of both right and left ventricular enlargement was common. Other workers have confirmed these findings, and since the introduction of effective methods of surgical closure, much attention has also been paid to the relation of the cardiographic changes to the degree of associated pulmonary vascular disorder.

Char, Adams, and Anderson (1959) noted some association between right ventricular hypertrophy and pulmonary vascular disease, but did not find strong correlations between cardiographic patterns and physiological data: their series is notable for having lung biopsies from 54 patients at operation. Fyler et al. (1958) found the cardiogram useful in selecting patients for operation and considered that pure right ventricular hypertrophy in those without pulmonary stenosis "almost excludes the possibility of surgery". Toscano-Barboza and DuShane (1959) found that the pattern of right ventricular diastolic overload was produced by defects that were situated in the inflow portion of the ventricle or were associated with tricuspid regurgitation. They concluded that "Precise quantitative correlation could not be established between the electrocardiographic criteria and the data for pulmonary arterial pressure or for pulmonary vascular resistance." DuShane et al. (1960) reported on 100 surgically treated patients with pulmonary hypertension: after closure of the defect the pulmonary arterial systolic pressure decreased to 70 per cent or less of the systemic pressure in 88 out of 90 with the electrocardiogram of "left ventricular overwork" but in only 2 out of 10 without this pattern.

Blount and Woodwark (1960), however, found that lone left ventricular hypertrophy might be associated with considerable elevation of pulmonary vascular resistance. They noted, as did Dack (1960) and Vince and Keith (1961), that lone right ventricular hypertrophy was always associated with severe pulmonary vascular disease.

It has long been realized that pulmonary vascular disease is a serious hazard to successful surgical treatment, and it has been shown (Cleland et al., 1958; Goodwin, 1961) that the single most important factor in determining the operative risks and results is the degree of pulmonary vascular disorder before operation, as judged by the length of the systolic murmur, the pulmonary vascular resistance, and the fall of pulmonary arterial pressure immediately after closure. If such disorder is present, the patient will have substantial pulmonary hypertension after the defect is closed, and the operative risk is high. Furthermore, the level of the pulmonary arterial pressure immediately after closure of the defect usually agrees well with the pressure measured at catheterization months or years later, indicating that the immediate fall in pressure is a good index of the degree of pulmonary vascular disease (Hollman, 1961). 
The object of this communication is to analyse the value of the cardiogram in predicting the degree of pulmonary vascular disorder, the amount by which the pulmonary arterial pressure will fall immediately after closure, and the risks of operation. Mention is also made of special cardiographic features that may suggest complicated types of defect or associated cardiac lesions that may influence the surgical management.

\section{MATERIAL AND METHODS}

The electrocardiograms of 82 consecutive patients whose ventricular septal defect was successfullyclosed were analysed from the following points of view.

1. Signs thought to indicate a large left-to-right shunt:

(a) deep $Q$

(b) tall $\mathrm{R}$

(c) peaked $\mathrm{T}$

(d) left axis deviation in leads $\mathrm{V} 4$ to $\mathrm{V} 7$

2. Signs of increased "pressure" work by the right ventricle (due to pulmonary vascular disease, or pulmonary stenosis):
(a) tall $\mathrm{R}$ and small $\mathrm{S}$, or $\mathrm{R}, \mathrm{qR}$, or $\mathrm{rR}^{\prime}$, in leads $\mathrm{V} 4 \mathrm{R}$ and $\mathrm{V1}$
(b) $T$ wave changes in V4R to V3
(c) deep $\mathrm{S}$ in V6
(d) right axis deviation

3. Other cardiographic signs:
(a) bundle-branch block.
(b) high voltage in limb leads
(c) abnormal $\mathbf{P}$ waves, indicating atrial enlargement.

We have used as our index of severity of pulmonary vascular disease the post-operative mean pulmonary arterial pressure expressed as a percentage of the mean systemic pressure. On the basis of this percentage the patients were divided into (a) mild, 10 to 29 per cent (44 patients); (b) moderate, 30 to 49 per cent (28 patients); (c) severe, 50 per cent and over (10 patients). The pressures were measured at the time of the operation.

\section{RESULTS}

These are presented in the following tables and in most instances the electrocardiographic sign under consideration has been related to the index of pulmonary vascular disease as previously defined. The numerals in the tables show the number of patients in each category.

\section{Group 1: Left Pracordial Leads, V5 to V7}

Size of $Q$ Wave. A simple grading according to presence or absence of the $Q$ wave gave no indication of the severity of pulmonary disease. However, when graded according to actual depth (Table I) it seemed likely that a deep Q wave, $5 \mathrm{~mm}$. or more, was a good indication that there would not be severe pulmonary hypertension after operation. A small or absent $Q$ wave on the other hand occurred commonly in both the mild and the severe groups and gave little prognostic information.

TABLE I

Distribution of 82 Cases of VSD Based on Depth of Q WaVe in Leads V5 to V7

\begin{tabular}{|c|c|c|c|c|c|c|}
\hline \multicolumn{4}{|c|}{ Deepest $Q$ wave in V5 to V7 } & \multicolumn{3}{|c|}{$\begin{array}{l}\text { Pulmonary arterial mean pressure (percentage of } \\
\text { systemic) after closure of defect }\end{array}$} \\
\hline & & & & \multirow{2}{*}{$\begin{array}{c}10 \% \text { to } 29 \% \\
22 \text { cases } \\
13 \% " \\
9 \% "\end{array}$} & $\frac{30 \% \text { to } 49 \%}{14 \text { cases }}$ & $\frac{50 \% \text { and over }}{7 \text { cases }}$ \\
\hline $\begin{array}{l}0-1 \mathrm{~mm} . \\
2-4 \mathrm{~mm} . \\
5 \mathrm{~mm} \text {. or over }\end{array}$ & $\begin{array}{l}\cdots \\
\cdots \\
\cdots\end{array}$ & $\begin{array}{l}\cdots \\
\cdots \\
\cdots\end{array}$ & $\begin{array}{l}\cdots \\
\cdots\end{array}$ & & $\begin{array}{c}14 \text { cases } \\
10 ", \\
4 \%\end{array}$ & $\begin{array}{l}7 \text { cases } \\
1 \% \\
2 \%\end{array}$ \\
\hline
\end{tabular}


There was a tendency for patients with an associated patent ductus who had prominent $\mathrm{Q}$ waves to have more severe pulmonary vascular disease than the patients with uncomplicated defects. Of the 15 patients with a $\mathrm{Q}$ wave of $5 \mathrm{~mm}$. or more, only 2 had severe pulmonary hypertension after operation and both had an associated patent ductus. The only correlation between the depth of the $\mathrm{Q}$ wave and the size of the defect was that patients with a defect of less than $1 \mathrm{~cm} . / \mathrm{m} .^{2}$ of body surface area had uniformly small $Q$ waves.

An $R$ wave of over $30 \mathrm{~mm}$. in leads $V 5$ to $V 7$ was taken to be abnormally tall. Of patients with a tall $\mathrm{R}$ wave in any of these leads, 8 had mild, 5 had moderate, and none had severe pulmonary hypertension after operation. A tall $\mathrm{R}$ wave in these leads was thus a good guide to the absence of pulmonary vascular disease, but only 15 per cent of the patients in the mild group had $R$ waves of this dimension.

Peaking of the $T$ waves is difficult to define by arithmetic criteria, and examples are shown in Fig. 1, 2, and 4. An arbitrary grading into absent, $1+, 2+$, and $3+$ was made, and to maintain uniformity this was done by one author alone. The results of the analysis are shown in Table II. It can be seen in those patients with slight or no peaking there is a preponderance of those with moderate or severe pulmonary hypertension after operation, and when peaking is $2+$ or $3+$ there tend to be relatively more in the good risk, low pressure, group. However, the division of the patients on the basis of $\mathrm{T}$ wave peaking is by no means clear cut and it can be a misleading sign, as shown in Fig. 3.

An electrical axis between $0^{\circ}$ and $-180^{\circ}$ was found in 11 patients. None of these were in the severe group, whilst 7 were in the mild group (Table VII). The presence of left axis deviation was thus a strong contraindication to severe pulmonary vascular disease.

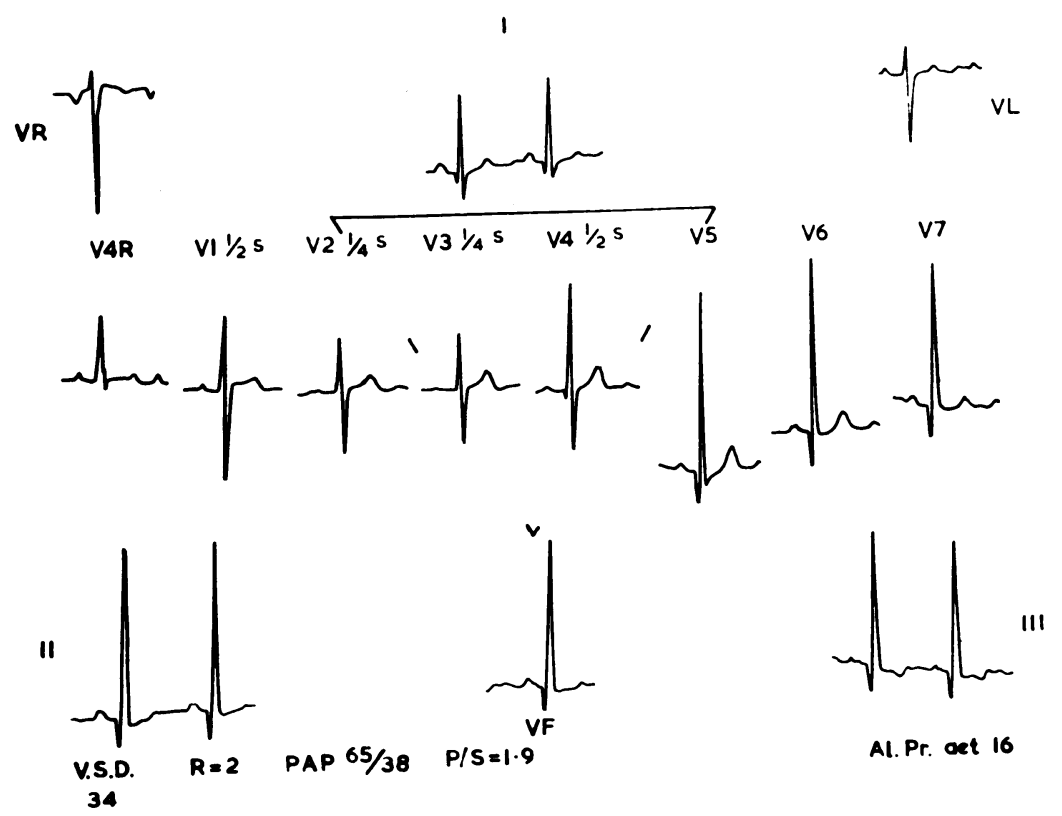

FIG. 1.-Deep $Q$ waves and tall $R$ waves in V5 to V7 indicate that there is only slight pulmonary vascular disease. $\mathrm{T}$ in V5 is slightly peaked $(1+)$. In this and subsequent figures, P.A.P.=pulmonary arterial pressure at catheterization, $\mathbf{R}=$ pulmonary arteriolar resistance in units, $P / S=$ pulmonary to systemic flow ratio, P.A.P. after=pulmonary arterial mean pressure after operation as a percentage of systemic mean pressure. 
I<smiles>[R]C(C)C(C)CC</smiles><smiles>CCCCC(C)CC</smiles><smiles>CCCCCC</smiles><smiles>[R10]CC(C)C(C)C(C)C(C)C</smiles><smiles>[Y10]C[AsH2]</smiles>

\section{v5}

V6 $\quad$ v7

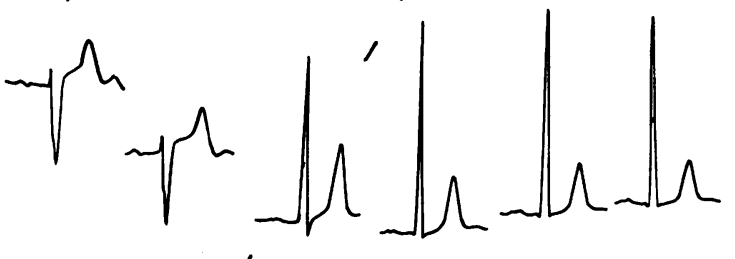

II<smiles>CCC(C)(C)CCCC(C)C(C)C</smiles><smiles>CCC(C)C(C)C</smiles><smiles>CCCC1CCCCCC1C</smiles>

V.S.D.

VF

Pe. Har. oet 34

28 R 1.3 PAP $45 / 15$ P/S 2.6 PAP after 20\%

FIG. 2.-The rS pattern in V1, the tall $R$ waves in V5 to V7, and the left axis deviation are all strong points in favour of the pulmonary arterial pressure being low after closure of the defect. $\mathrm{T}$ in V4 and V5 is strongly peaked $(3+)$.

I<smiles>CCCC(C)C</smiles>

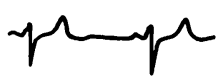<smiles>CC1(C)CCCCCCCCCC1</smiles>

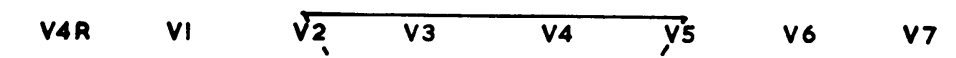

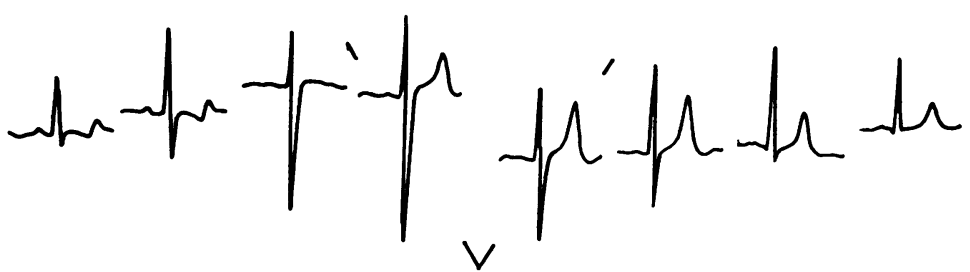

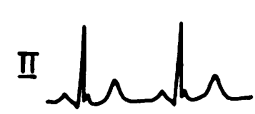

V.S.D.

$R=9$ units<smiles>CCCCCC</smiles><smiles>CCCCCCCCCC(C)C</smiles>

VF

23 PAP $9 \% / 62$ PAP ofter $63 \%$

M.S-K. aet.21 221242

FIG. 3.-The obvious right axis deviation of $+115^{\circ}$ is an unfavourable sign especially when taken with the Rs pattern in V1 and lack of a deep $Q$ or tall $R$ in V5 to V7. This patient had very severe pulmonary vascular disease (necropsy proof) showing that the strongly peaked $T$ wave in V5 was a misleading guide. 


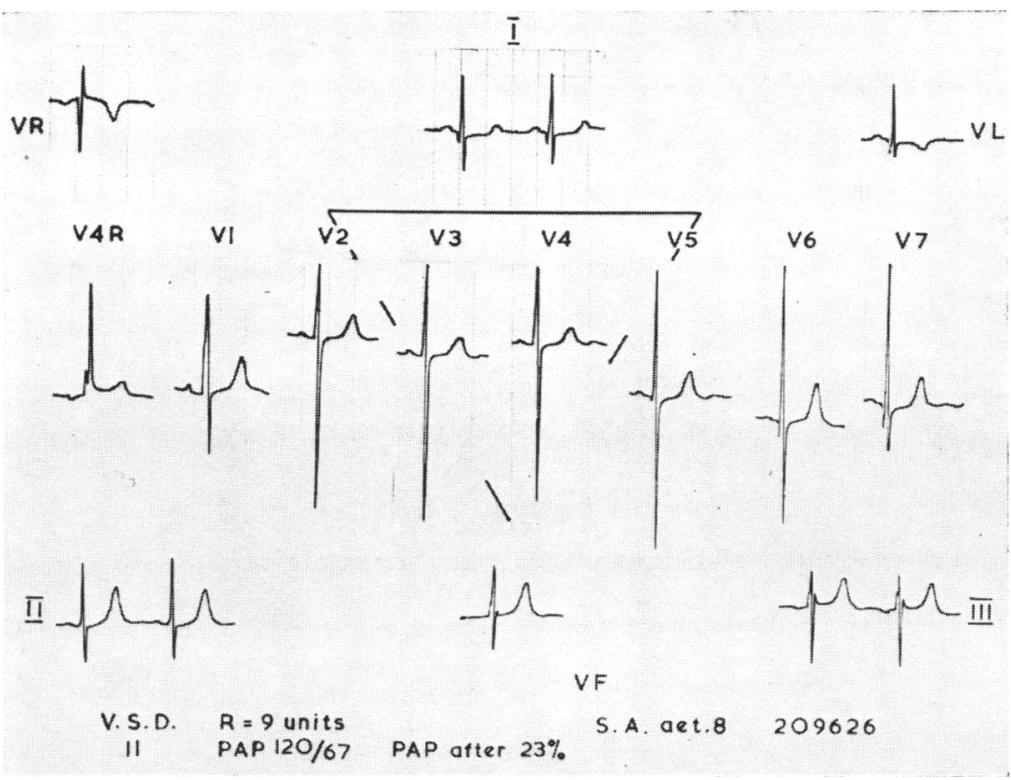

FIG. 4.-This patient had severe pulmonary hypertension (120/67) at catheterization. However, the cardiogram showed the favourable features of left axis deviation (axis $-30^{\circ}$ ), and deep $Q$ waves and tall $R$ waves in V6 to V7. After closure the pulmonary arterial pressure was $33 / 17$, the mean pressure being 23 per cent of the systemic. T in V6 was moderately peaked $(2+)$.

TABLE II

Degree of Peaking of T Wave in Leads V5 to V7 Analysed in Four Grades in 82 Cases of VSD

\begin{tabular}{|c|c|c|c|c|c|c|c|}
\hline \multicolumn{5}{|c|}{ Degree of $T$ wave peaking } & \multicolumn{3}{|c|}{$\begin{array}{l}\text { Pulmonary arterial mean pressure (percentage of } \\
\text { systemic) after closure of defect }\end{array}$} \\
\hline & & & & & $10 \%$ to $29 \%$ & $30 \%$ to $49 \%$ & $50 \%$ and over \\
\hline $\begin{array}{l}0 \\
1+\cdots \\
2+\cdots \\
3+\ldots\end{array}$ & $\begin{array}{l}\because \\
\because \\
\ddot{.}\end{array}$ & $\begin{array}{l}\because \\
\because \\
\therefore \\
.\end{array}$ & $\begin{array}{l}\cdots \\
\cdots \\
\cdots \\
.\end{array}$ & $\begin{array}{l}\because \\
\because \\
\cdots\end{array}$ & 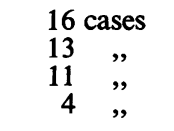 & $\begin{array}{c}17 \text { cases } \\
7 \\
3 \quad, \\
1 \quad,\end{array}$ & 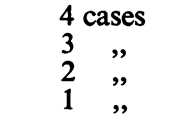 \\
\hline
\end{tabular}

\section{Group 2: Right Pracordial Leads, V4R and V1}

Pulmonary stenosis alone has a profound effect on the $R S$ pattern in V1, and therefore the 14 patients with clearcut obstruction to right ventricular outflow are considered separately.

The patients without pulmonary stenosis were separated into groups according to the relative sizes of the R and S waves in V1, as shown in Table III. Most of those with an rS pattern in V1 had a low pulmonary arterial pressure after operation, only 1 out of 21 being in the high pressure group and 4 in the intermediate pressure group. When $\mathrm{R}$ and $\mathrm{S}$ were equal there were more in the intermediate group, while when $R$ exceeded $S$ there were appreciable numbers in the high pressure group. When $\mathrm{S}$ was absent there were few in the good risk group. Similar results were obtained from an analysis of the findings with lead V4R. Conversely in only 1 of the 10 patients who had severe pulmonary hypertension post-operatively was there an rS pattern in $\mathrm{V} 1(\mathrm{R}=34 \mathrm{~mm}$., $\mathrm{S}=44 \mathrm{~mm}$.), in $2, R$ and $S$ were equal, and in $7 \mathrm{R}$ was greater than $\mathrm{S}$. 
TABLE III

V1 Pattern in 68 Cases of VSD Without Pulmonary Stenosis

\begin{tabular}{|c|c|c|c|c|c|c|}
\hline \multicolumn{4}{|c|}{ V1 pattern } & \multicolumn{3}{|c|}{$\begin{array}{l}\text { Pulmonary arterial mean pressure (percentage of } \\
\text { systemic) after closure of defect }\end{array}$} \\
\hline & & & & $10 \%$ to $29 \%$ & $30 \%$ to $49 \%$ & $50 \%$ and over \\
\hline 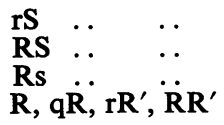 & $\begin{array}{l}\ldots \\
\cdots \\
\cdots\end{array}$ & $\begin{array}{l}. . \\
\therefore \\
.\end{array}$ & $\begin{array}{l}. \\
. \\
.\end{array}$ & $\begin{array}{c}16 \text { cases } \\
6 ", \\
6 ", \\
1 ",\end{array}$ & $\begin{array}{c}4 \text { cases } \\
7 \stackrel{ }{12}, \\
5^{*} ",\end{array}$ & $\begin{array}{l}2 \text { cases } \\
2 \\
3 \\
4 \Rightarrow\end{array}$ \\
\hline
\end{tabular}

* Two with qR had corrected transposition.

TABLE IV

V1 Pattern and Average Right Ventricular Pressure before Operation in 14 Cases of VSD with PULMONARY STENOSIS

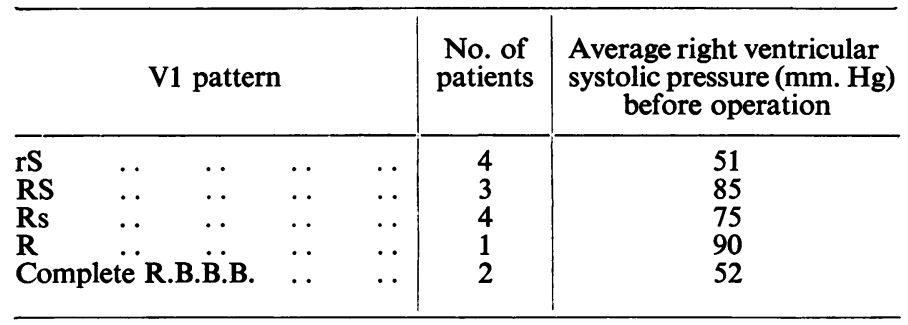
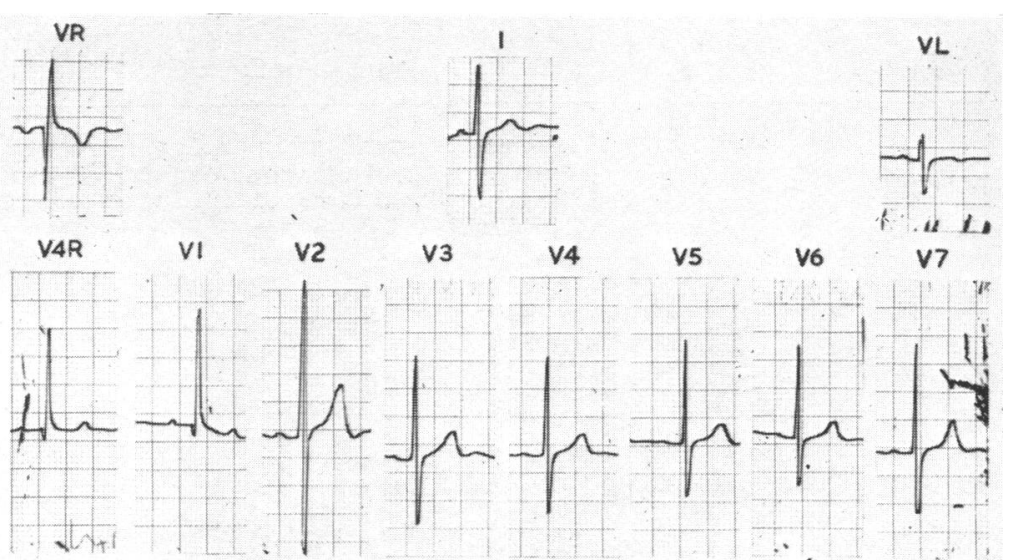

V7

II
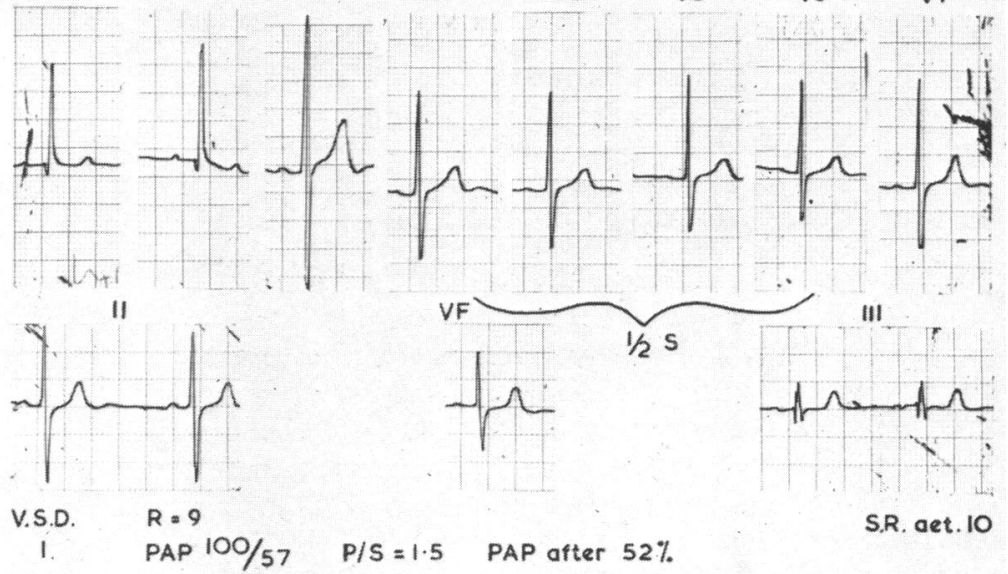

S.R. aet. 10

FIG. 5.-There is right axis deviation, with a $\mathrm{qR}$ complex in $\mathrm{V} 1$ and a prominent $\mathrm{S}$ in $\mathrm{V} 5$ to V7. These are all unfavourable signs. 


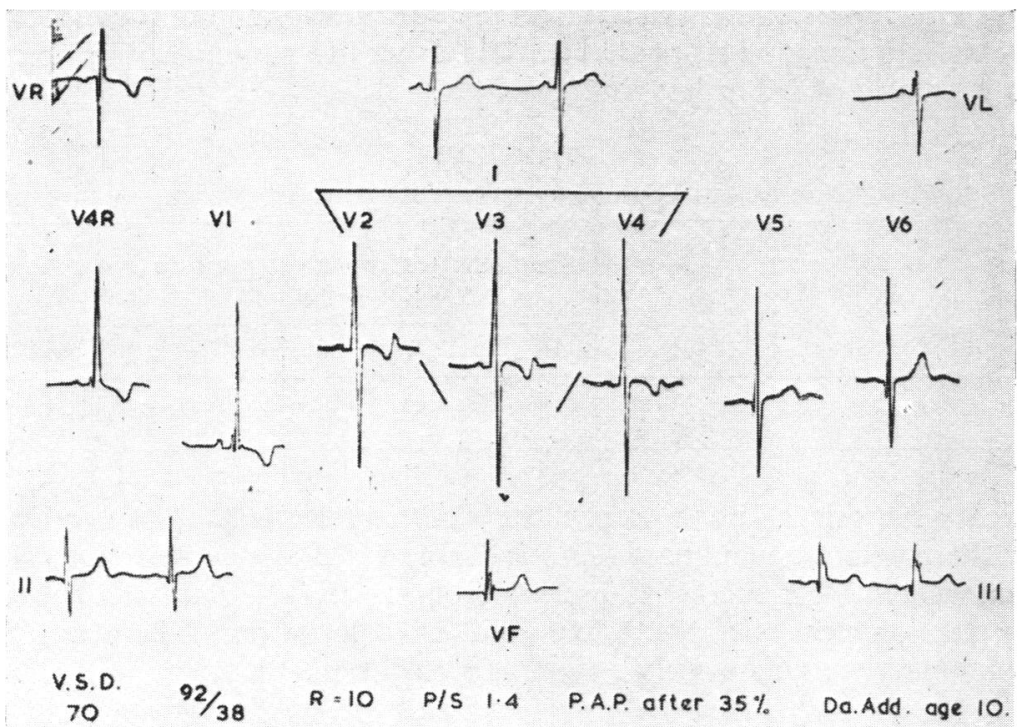

FIG. 6.-This cardiogram shows well the notched base to the $R$ wave in V4R and V1 that is a sign of severe pulmonary vascular disease in patients without pulmonary stenosis. Note also the right axis deviation.

TABLE V

Peaking of T Wave in Lead V1 in 82 Patients with VSD (14 WITH Associated Pulmonary Stenosis)

\begin{tabular}{|c|c|c|c|c|c|c|c|}
\hline \multicolumn{5}{|c|}{ Peaking of $\mathrm{T}$ wave in $\mathrm{V} 1$} & \multicolumn{3}{|c|}{$\begin{array}{l}\text { Pulmonary arterial mean pressure (percentage of } \\
\text { systemic) after closure of defect }\end{array}$} \\
\hline & & & & & \multirow{2}{*}{ 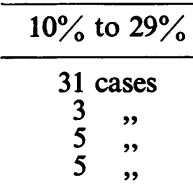 } & $30 \%$ to $49 \%$ & $\frac{50 \% \text { and over }}{5 \text { cases }}$ \\
\hline $\begin{array}{l}\text { Absent } \\
1+\quad \cdots \\
2+\quad \cdots \\
3+\quad \cdots\end{array}$ & $\begin{array}{l}\cdots \\
\cdots \\
\cdots\end{array}$ & $\begin{array}{l}\cdots \\
\cdots \\
\cdots\end{array}$ & $\begin{array}{l}\cdots \\
\cdots \\
\cdots\end{array}$ & $\begin{array}{l}\cdots \\
\cdots \\
\cdots\end{array}$ & & $\begin{array}{c}18 \text { cases } \\
5 \% " \\
3 \% \\
2 ",\end{array}$ & $\begin{array}{l}5 \text { cases } \\
32 " \\
2 \% \\
0 \%\end{array}$ \\
\hline
\end{tabular}

The 14 patients with pulmonary stenosis (valvular or infundibular) were similarly classified according to the RS pattern in V1 and the average right ventricular systolic pressure (Table IV). It can be seen that those with an rS pattern or with complete right bundle-branch block had on the average lower pressures than those patients with equal or dominant $R$ waves.

'Peaking' of the $T$ wave was found in 28 patients and was arbitrarily divided into four grades, as shown in Table V. None with severe peaking lay in the high pressure group, but otherwise there was little correlation between this sign and the post-operative pulmonary arterial pressure. Inversion of the T wave was analysed according to whether such inversion was present in one or more leads. There was little correlation between $T$ wave inversion and the various pressure groups. In fact, the majority of those with a high pulmonary pressure after operation had $\mathrm{T}$ waves that were normal or slightly to moderately peaked.

Considering still the evidence of right ventricular hypertrophy the R/S ratio in lead V6 was measured in those without pulmonary stenosis. An $\mathrm{R} / \mathrm{S}$ ratio in this lead of 2.0 or less was taken to indicate an unduly prominent $\mathrm{S}$ wave, and the results are shown in Table VI. Half the patients in the severe group had this feature compared with a third in the mild and moderate groups. A deep 
$S$ wave in V6 was thus more common in the high pressure group than in the others, but was nevertheless quite common in the good risk patients. A further five patients with associated pulmonary stenosis had an $\mathrm{R} / \mathrm{S}$ ratio of 2.0 or less in V6.

TABLE VI

R/S Ratio of 2 or Less in V6 in 68 Cases of VSD without Pulmonary Stenosis

\begin{tabular}{|c|c|c|c|c|c|}
\hline & \multirow{2}{*}{\multicolumn{2}{|c|}{$\mathbf{R} / \mathrm{S}$ in $\mathbf{V} 6$}} & \multicolumn{3}{|c|}{$\begin{array}{l}\text { Pulmonary arterial mean pressure (percentage of } \\
\text { systemic) after closure of defect }\end{array}$} \\
\hline & & & $10 \%$ to $29 \%$ & $30 \%$ to $49 \%$ & $50 \%$ and over \\
\hline 2.0 or less & .. & .. & 10 of 32 cases & 7 of 25 cases & 5 of 11 cases \\
\hline
\end{tabular}

Since pulmonary stenosis is known to produce right axis deviation, the electrical axis has been analysed only in those without pulmonary stenosis (Table VII). Twenty-six had right axis deviation and most of them were in the moderate and severe groups. In fact, 9 out of 10 of those with severe pulmonary hypertension post-operatively had right axis deviation. There were, in addition, 6 patients with pulmonary stenosis who had right axis deviation.

TABLE VII

Electrical Axis in 68 Cases of VSD without Pulmonary Stenosis

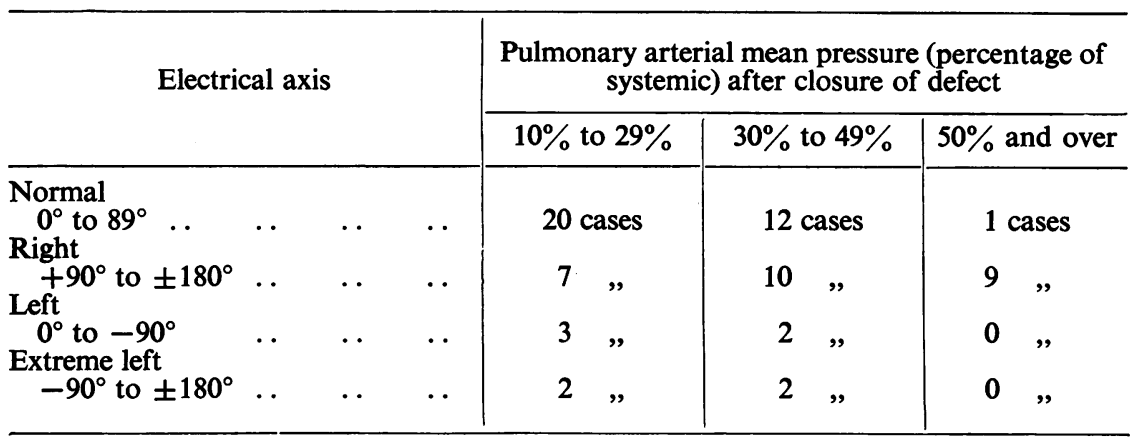

\section{Group 3: other Cardiographic Signs}

Left bundle-branch block was never encountered, but right branch block was found in 15 , being complete in five. Only 1 patient with right branch block was in the severe group, while there were 4 in the moderate group, and 10 in the mild group.

In a patient who was found at operation to have two large ventricular defects we had observed that there were large diphasic complexes in the limb leads. Among the whole series there were 11 patients in whom both the $R$ and $S$ waves measured more than $20 \mathrm{~mm}$. in one or more of the limb leads, and only 3 of these patients had anatomically uncomplicated defects. Seven had a lesion that could increase the left-to-right shunt: patent ductus in 4, multiple ventricular defects in 2, and an atrial septal defect in one. One had pulmonary stenosis. An example of this unusual type of cardiogram is shown in Fig. 9.

$P$ Wave. One had atrial fibrillation, and of the other 81 patients, 24 showed hypertrophy of the left atrium, 16 of the right atrium, and 4 of both atria. Those with right atrial hypertrophy tended to have rather more in the intermediate pressure group, but otherwise there was no correlation between the $\mathbf{P}$ waves and post-operative pulmonary hypertension (Table VIII). The two patients with associated severe mitral stenosis (one requiring valvotomy) had entirely normal $P$ waves. The only patients with a marked degree of left atrial enlargement had associated severe mitral regurgitation. 
<smiles>CCCCC(C)C(C)C</smiles>
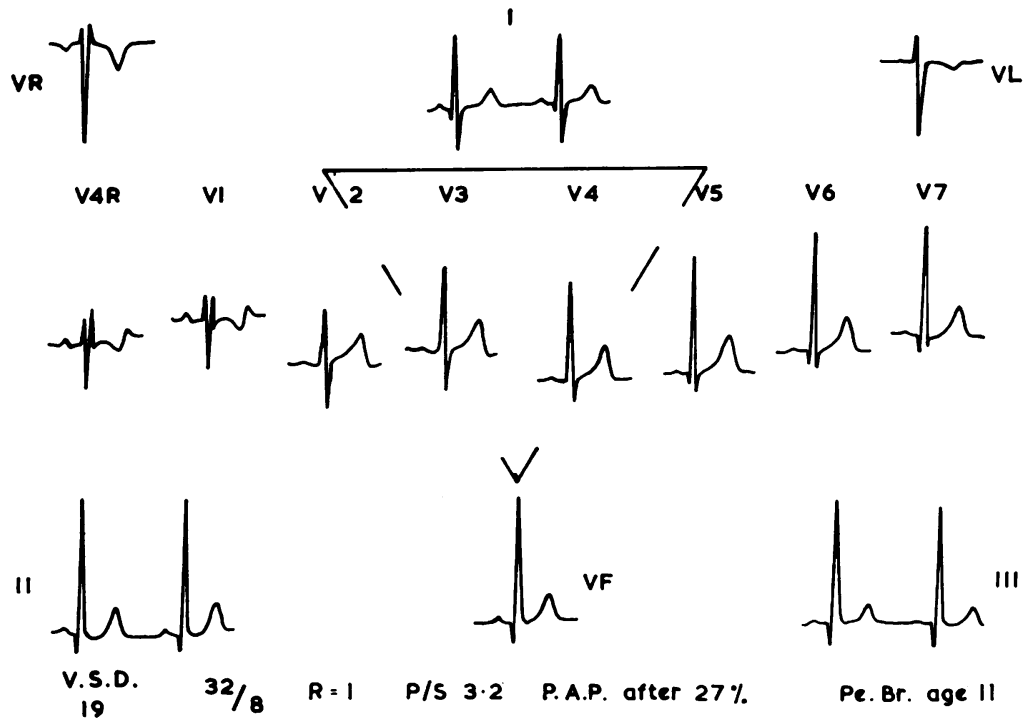

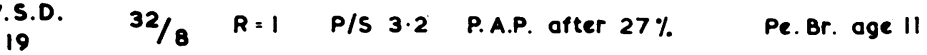

Fig. 7.-Partial right bundle-branch block is shown in this tracing. It is a favourable electrocardiographic sign.

TABLE VIII

ANalysis of 44 Cases of VSD where P Waves Showed Atrial Hypertrophy

\begin{tabular}{|c|c|c|c|c|c|c|}
\hline \multicolumn{4}{|c|}{ Atrial hypertrophy } & \multicolumn{3}{|c|}{$\begin{array}{l}\text { Pulmonary arterial mean pressure (percentage of } \\
\text { systemic) after closure of defect }\end{array}$} \\
\hline & & & & $10 \%$ to $29 \%$ & $30 \%$ to $49 \%$ & $50 \%$ and over \\
\hline $\begin{array}{l}\text { Left } \\
\text { Right } \\
\text { Left and right }\end{array}$ & $\begin{array}{l}\cdots \\
\cdots \\
\cdots\end{array}$ & $\begin{array}{l}\cdots \\
\cdots \\
\cdots\end{array}$ & $\begin{array}{l}\cdots \\
\cdots \\
\cdots\end{array}$ & $\begin{array}{c}15 \text { cases } \\
7 \\
2\end{array}$ & $\begin{array}{l}7 \text { cases } \\
8 \quad, \\
0\end{array}$ & $\begin{array}{l}3 \text { cases } \\
1 \quad, \\
1 \quad,\end{array}$ \\
\hline
\end{tabular}

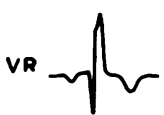<smiles>CCCCCCC(C)CC=C(C)C</smiles><smiles>CCCC1CCCC1(C)C</smiles>

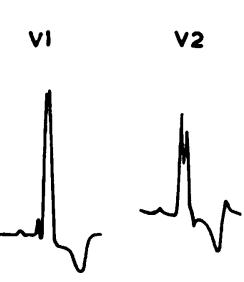
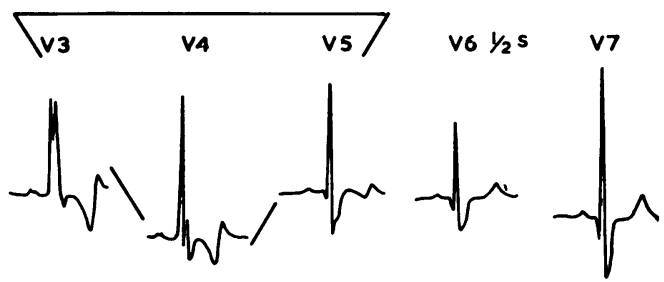

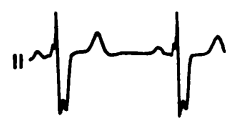<smiles>CC(C)[Al]([I+])C[18F]</smiles>

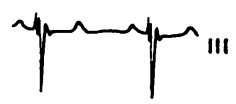

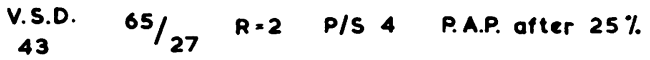

Le. Ph. age 13 .

FIG. 8.-Complete right bundle-branch block was found in five patients. 


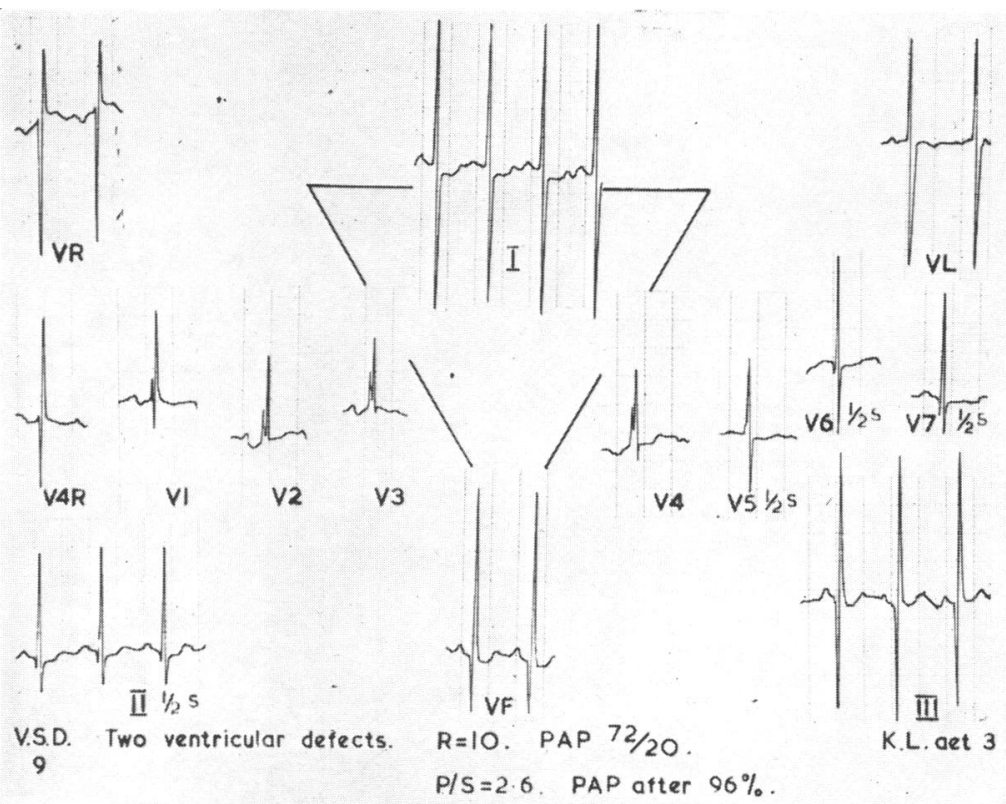

FIG. 9.-An example of large diphasic limb lead complexes from a patient with two large ventricular septal defects.

Cardiographic Features of Patients with Severe Post-operative Pulmonary Hypertension

The preceding correlations have taken the electrocardiogram as the primary feature from which the analysis was made. This, of course, is the way in which the electrocardiogram has to be used in practice. However, it is of interest to show the details of the 10 patients whose pulmonary arterial pressure was over half of the systemic pressure after closure of the defect (Fig. 10 and Table IX).

TABLE IX

Height of Q, R, and S Waves in Pracordial Leads, Electrical Axis, T Wave Peaking, and P Wave Abnormality in 10 Cases of VSD where Post-operative Pulmonary Arterial Pressure was 50 per Cent OR MORE OF SYSTEMIC PRESSURE

\begin{tabular}{|c|c|c|c|c|c|c|c|c|c|c|c|c|}
\hline \multirow{2}{*}{$\begin{array}{l}\text { Case } \\
\text { No. }\end{array}$} & \multicolumn{2}{|c|}{ V4R } & \multicolumn{2}{|c|}{ V1 } & \multicolumn{3}{|c|}{ V6 } & \multirow{2}{*}{ Axis } & \multicolumn{2}{|c|}{$\mathrm{T}$ wave peaking } & \multirow{2}{*}{ P wave } & \multirow{2}{*}{$\begin{array}{l}\text { Associated } \\
\text { cardiac } \\
\text { lesion }\end{array}$} \\
\hline & $\mathbf{R}$ & $\mathbf{S}$ & $\mathbf{R}$ & $\mathbf{S}$ & $\mathbf{Q}$ & $\mathbf{R}$ & $\mathbf{S}$ & & V1 & V4-V6 & & \\
\hline $\begin{array}{r}1 \\
7 \\
14 \\
20\end{array}$ & $\begin{array}{r}* 18 \\
8 \\
17 \\
13\end{array}$ & $\begin{array}{l}0 \\
0 \\
1 \\
7\end{array}$ & $\begin{array}{r}21 \\
8 \\
23 \\
22\end{array}$ & $\begin{array}{r}0 \\
5 \\
10 \\
14\end{array}$ & $\begin{array}{l}0 \\
3 \\
6 \\
9\end{array}$ & $\begin{array}{l}16 \\
17 \\
26 \\
25\end{array}$ & $\begin{array}{r}8 \\
4 \\
15 \\
2\end{array}$ & $\begin{array}{r}+90^{\circ} \\
+80^{\circ} \\
+110^{\circ} \\
+90^{\circ}\end{array}$ & $\begin{array}{l}1+ \\
\downarrow \text { to } \mathrm{V3} \\
\mathbf{0} \\
0\end{array}$ & $\begin{array}{l}2+ \\
2+ \\
2+ \\
3+\end{array}$ & $\begin{array}{c}\mathbf{N} \\
\text { LA 1 1+ }^{-} \\
\mathbf{N} \\
\mathbf{N}\end{array}$ & $\begin{array}{l}\text { Patent ductus } \\
\text { Patent ductus, } \\
\text { pulmonary }\end{array}$ \\
\hline $\begin{array}{l}23 \\
54 \\
64 \\
76 \\
77 \\
78\end{array}$ & $\begin{array}{r}11 \\
12 \\
27 \\
9 \\
22 \\
* 13\end{array}$ & $\begin{array}{l}2 \\
7 \\
0 \\
7 \\
0 \\
0\end{array}$ & $\begin{array}{l}16 \\
14 \\
32 \\
10 \\
32 \\
33\end{array}$ & $\begin{array}{r}8 \\
22 \\
1 \\
8 \\
0 \\
0\end{array}$ & $\begin{array}{r}1 \\
12 \\
0 \\
1 \\
1 \\
0\end{array}$ & $\begin{array}{l}19 \\
21 \\
18 \\
16 \\
15 \\
20\end{array}$ & $\begin{array}{r}2 \\
1 \\
8 \\
11 \\
10 \\
10\end{array}$ & $\begin{array}{r}+110^{\circ} \\
+90^{\circ} \\
+100^{\circ} \\
+100^{\circ} \\
+100^{\circ} \\
+85^{\circ}\end{array}$ & $\begin{array}{l}0 \\
0 \\
\downarrow \\
\downarrow \\
1+ \\
1+\end{array}$ & $\begin{array}{l}2+ \\
\downarrow \\
0 \\
0 \\
0 \\
0\end{array}$ & $\begin{array}{c}\mathbf{N} \\
\mathbf{L A} \\
\mathbf{N} \\
\mathbf{N} \\
\mathbf{N} \\
\mathbf{N A} \\
\mathbf{R A}\end{array}$ & $\begin{array}{l}\text { stenosis } \\
\text { Patent ductus } \\
\text { Mitral stenosis } \\
\begin{array}{l}\text { Stenosis of right } \\
\text { pulmonary } \\
\text { artery }\end{array}\end{array}$ \\
\hline
\end{tabular}

* $=\mathrm{Q}$ wave present also.

$\mathbf{N}=$ normal. 

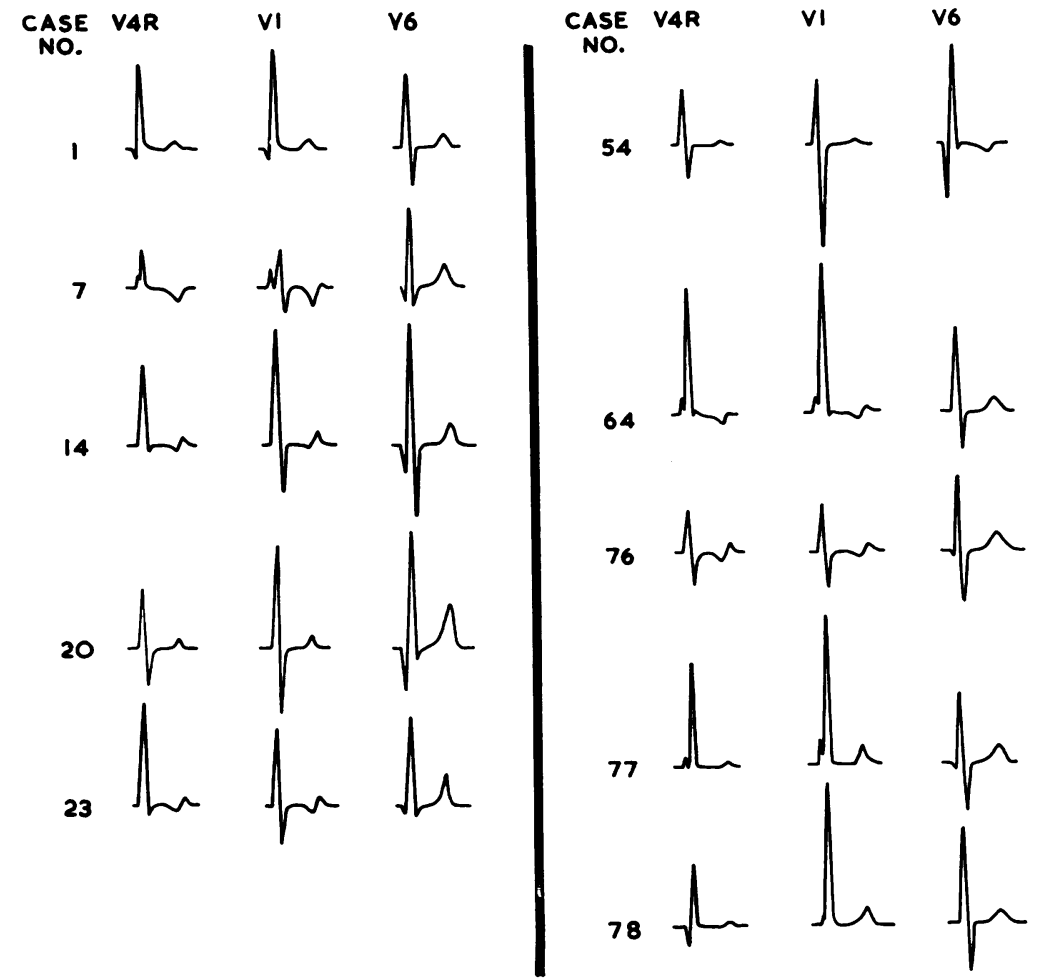

FIG. 10.-Facsimiles of leads V4R, V1, and V6 in 10 patients who had severe pulmonary hypertension after complete closure of the ventricular septal defect. (All complexes are drawn to the same scale.)

The absence of large $\mathrm{Q}$ waves in V5 to V7 in all but 2 patients is striking, and it is interesting that both of these had an associated patent ductus. None had a tall R in V6 while 6 had quite deep $\mathrm{S}$ waves. No less than 5 showed the allegedly favourable sign of peaked $\mathrm{T}$ waves in V4 to V6, thus demonstrating its unreliability. All had an electrical axis that was close to, or over, $+90^{\circ}$. The $P$ waves generally were inconspicuous, being normal in 7, and showing more than a slight degree of left atrial hypertrophy in three. In the right præcordial leads V4R and V1 the $R$ wave was greater than the $S$ wave with one exception, and 2 patients had a $Q$ wave in these leads. The $T$ wave in V4R and V1 was variable. Only one patient had partial right bundle-branch block, and none had complete bundle-branch block.

Site of the Defect. Most of the patients had a lone infracristal defect, in 2 muscular, but in 5 it was supracristal and in 7 there were multiple defects.

As previously mentioned there were large diphasic limb lead complexes in 2 of the 7 with multiple ventricular defects, but apart from this the site of the defect had no recognizable effect on the electrocardiogram. One of the muscular defects was however due to indirect trauma, and the acute nature of the lesion gave a cardiogram of a type not seen in the other patients in that it showed considerable tachycardia and clockwise rotation. This patient has been reported elsewhere (Cleland et al., 1961).

Associated Cardiac Lesions. Eleven patients had a patent ductus arteriosus, and in 3 of these the $\mathrm{Q}$ wave in V5 to V7 was unexpectedly deep considering the severity of the post-operative pulmonary hypertension. In 4 there were large diphasic limb lead complexes.

There were 2 patients with atrial septal defect and neither showed right bundle-branch block. 
Seven patients had associated aortic regurgitation but none had cardiograms outside the usual range for ventricular septal defect. Only one had left axis deviation. However, the series is selected since none with severe regurgitation were submitted to operation, and in one non-operated patient with severe regurgitation there was gross ST depression in V6.

Four of the group had severe mitral stenosis or regurgitation and the $\mathrm{P}$ waves in these have already been mentioned. Two with corrected transposition showed cardiograms typical of the anomaly and are reported elsewhere (Morgan et al., 1962).

\section{Patients with Lone Right, or Lone Left, Ventricular Hypertrophy}

Excluding those with pulmonary stenosis there were 16 with lone right ventricular hypertrophy, the children being judged by the criteria of Hollman (1958). Of these 16, there were 3 with severe, 12 with moderate, and only 1 with slight or no pulmonary hypertension after operation.

Conversely 24 patients had lone left ventricular hypertrophy as judged by the presence of deep Q waves or tall $\mathrm{R}$ waves in V5 to V7, or of left axis deviation. Peaking of the T wave in V5 to V7 was not used as a criterion. As shown in Table $X$ only one of these patients (and he had an associated patent ductus) had severe pulmonary hypertension after operation.

TABLE X

ANAlysis of 40 CASES of VSD with LONE Right or LONE Left Ventricular Hypertrophy

\begin{tabular}{|c|c|c|c|c|c|c|c|}
\hline \multicolumn{5}{|c|}{ Ventricular hypertrophy } & \multicolumn{3}{|c|}{$\begin{array}{l}\text { Pulmonary arterial mean pressure (percentage of } \\
\text { systemic) after closure of defect }\end{array}$} \\
\hline & & & & & $10 \%$ to $29 \%$ & $30 \%$ to $49 \%$ & $50 \%$ and over \\
\hline $\begin{array}{l}\text { Left only } \\
\text { Right only }\end{array}$ & $\begin{array}{l}\cdots \\
\cdots\end{array}$ & $\begin{array}{l}\cdots \\
\cdots\end{array}$ & $\begin{array}{l}\cdots \\
\cdots\end{array}$ & $\begin{array}{l}\cdots \\
\cdots\end{array}$ & $\begin{array}{c}17 \text { cases } \\
1 \quad,\end{array}$ & $\begin{array}{l}6 \text { cases } \\
12\end{array}$ & $\begin{array}{l}1 \text { cases } \\
3 \text {, }\end{array}$ \\
\hline
\end{tabular}

\section{Discussion}

This study has shown that the electrocardiogram is of use in predicting the severity of pulmonary vascular disease in ventricular septal defect and that some features are more reliable than others.

The presence of an rS pattern in V1 proved to be a remarkably good indication that the pulmonary arterial pressure would be low after operation as did other evidence of left ventricular hypertrophy such as a tall R in V6 and left axis deviation. This is in contrast to Blount and Woodwark (1960) who did not find it a reliable sign. They, however, related their findings to pulmonary vascular resistance as measured at catheterization, which we have found misleading, and have used the postoperative pulmonary arterial pressure instead.

Tall peaked T waves in V5 to V7 were ascribed by Cabrera and Monroy (1952), to " diastolic overload" of the left ventricle and have been taken to imply a large left-to-right shunt. Although this is true in some patients, there are others, such as the one shown in Fig. 3, in whom a tall T wave is found even when there is considerable pulmonary vascular disease. In fact, in Blount and Woodwark's series no less than a third of those with a tall $\mathrm{T}$ wave in V6 had considerable pulmonary hypertension.

The lack of right bundle-branch block in the patients with associated atrial septal defect was rather surprising and, in fact, may be atypical because Toscano-Barboza and Du Shane (1959) noted that 4 out of 7 patients with this combination had secondary $R$ waves in V1.

Atrial fibrillation was rare, being found in only one patient, a man of 22 with associated mild mitral stenosis. The four patients with severe mitral disease (all children) were in sinus rhythm. Complete heart block was found once, in association with a corrected transposition. The absence of broad $\mathbf{P}$ waves in those with severe pulmonary vascular disease has already been commented on, and 
this correlation was also noted by Blount and Woodwark. On the other hand, it was quite common to have patients with a large left-to-right shunt who did not have left atrial enlargement.

\section{SUMMARY}

The extent of pulmonary vascular disease in 82 patients with ventricular septal defect was judged by the level of the pulmonary arterial pressure after complete closure of the defect. Various electrocardiographic features in these patients have been related to the post-operative pulmonary arterial pressure.

Mild pulmonary vascular disease was strongly suggested by a $\mathrm{Q}$ wave deeper than $4 \mathrm{~mm}$. in V5 to $\mathrm{V} 7, \mathrm{R}$ wave greater than $29 \mathrm{~mm}$. in V5 to V7, left axis deviation, rS pattern in V1, right bundlebranch block, and lone left ventricular hypertrophy.

Severe pulmonary vascular disease was found in the presence of a dominant $\mathrm{R}$ wave in $\mathrm{V} 1$, right axis deviation, and deep S in V6. These signs, however, were found also in some mild cases. Lone right ventricular hypertrophy was virtually confined to patients with moderate or severe postoperative pulmonary hypertension.

Tall peaked $\mathrm{T}$ waves in V5 to V7 were commoner in the mild group, but occurred often enough in severe cases to make the sign unreliable as an isolated criterion.

Unusually deep Q waves in V5 to V7 occur when there is an associated patent ductus and they are then an unreliable guide to the pulmonary vasculature.

$T$ wave peaking and $T$ wave inversion in the right præcordial leads were poorly related to evidence of pulmonary vascular disease as were the $\mathrm{P}$ waves in all leads.

Large complexes in the limb leads commonly indicated an associated cardiac anomaly.

No single electrocardiographic feature can be completely relied upon in assessing the extent of pulmonary vascular disease. An appraisal of the cardiogram as a whole is necessary together with an appreciation of the fact that some features are more reliable than others.

We are grateful to our surgical colleagues, Mrs. H. H. Bentall, Mr. L. Bromley, Mr. W. P. Cleland, and Mr. H. Sayed for their help and co-operation. Mrs. Carole Bennett kindly prepared the illustrations, and Mr. Peter Stinton was responsible for many of the pressure measurements.

\section{REFERENCES}

Blount, S. G., Jr., and Woodwark, G. M. (1960). Amer. J. Cardiol., 5, 223.

Cabrera, E., and Monroy, J. R. (1952). Amer. Heart J., 43, 661 and 669.

Char, F., Adams, P., and Anderson, R. C. (1959). A.M.A.J. Dis. Child., 97, 48.

Cleland, W. P., Beard, A. J. W., Bentall, H. H., Bishop, M. B., Braimbridge, M. V., Bromley, L. L., Goodwin, J. F., Hollman, A., Kerr, W. F., Lloyd-Jones, E. B., Melrose, D. G., and Telivuo, L. J. (1958). Brit. med. J., 2 , 1369. , Ellman, P., Goodwin, J., and Hollman, A. (1961). Brit. J. Dis. Chest., 55, 17.

Dack, S. (1960). Amer. J. Cardiol., 5, 199.

DuShane, J. W., Weidman, W. H., Brandenburg, R. O., and Kirklin, J. W. (1960). Circulation, $22,49$.

Fyler, D. C., Rudolph, A. M., Wittenborg, M. H., and Nadas, A. S. (1958). Circulation, 18, 833.

Goodwin, J. F. (1961). Proc. roy. Soc. Med., 54, 783.

Hollman, A. (1958). Brit. Heart J., 20, 129.

(1961). Proc. roy. Soc. Med., 54, 787.

Morgan, J. J., Pitman, R., Goodwin, J. F., Steiner, R. E., and Hollman, A. (1962). Brit. Heart J. In the press.

Toscano-Barboza, E., and DuShane, J. W. (1959). Amer. J. Cardiol., 3, 721.

Vince, D. J., and Keith, J. D. (1961). Circulation, 23, 225.

Wood, P., Magidson, O., and Wilson, P. A. O. (1954). Brit. Heart J., 16, 387. 